\title{
CONCEPÇÕES DE PROFESSORES SOBRE O USO DE TECNOLOGIAS DIGITAIS NAS ESCOLAS DO ENSINO FUNDAMENTAL DO PARANÁ: O CASO DO ENSINO DAS CIÊNCIAS DA NATUREZA
}

\author{
D. M. OZELAME \\ Universidade Estadual de Londrina/PR \\ diegozelame@gmail.com*
}

Artigo submetido em outubro/2015 e aceito em fevereiro/2016

DOI: $10.15628 /$ holos.2016.3632

\section{RESUMO}

O objetivo dessa investigação foi o de estudar as concepções de professores da Rede Estadual da Educação do Estado do Paraná, sobre a utilização de tecnologias educacionais no ensino de Ciências da Natureza. As discussões foram realizadas com base no Programa Paraná Digital e no material disponível no Portal "Dia a Dia Educação”, concebido pela Secretaria de Estado da Educação do Estado do Paraná (SEED/PR). A coleta dos dados foi baseada em questões dissertativas e as narrativas dos sujeitos foram tratadas por meio da Análise Textual Discursiva. A investigação identificou que os professores não utilizam os computadores. Embora o Portal "Dia a Dia Educação" se mantenha atualizado, especialmente com material de Ciências da Natureza, a investigação apontou a falta de manutenção dos computadores por parte das Coordenações Regionais de Tecnologia na Educação (CRTE), o que compromete o uso desse material pelos professores na Escola.

PALAVRAS-CHAVE: Política pública, Tecnologia da educação, Ensino de Ciências.

\section{DEPLOYMENT OF NEW TECHNOLOGIES AS PUBLIC POLICY IN PARANÁ EDUCATION: A CASE STUDY IN TEACHING SCIENCE}

\begin{abstract}
The purpose of this research was to study teachers' conceptions of the State Network of Paraná State Education on the use of educational technology in the teaching of natural sciences. The discussions were based on the Paraná Digital Program and material available on the Portal "Dia a Dia Educação", designed by the State of the Paraná State Education (SEED/PR). Data collection was based on essay questions and the narratives of the
\end{abstract}

subjects were treated through Textual Analysis Discourse. The research identified that teachers do not use computers. Although the Portal "Dia a Dia educação" is kept updated, especially with natural sciences material, research pointed to the lack of maintenance of computers by the Coordination Regional Technology in Education (CRTE), which compromises the use of this material by teachers at school.

KEYWORDS: Public policy, Education technology, Science education. 


\section{INTRODUÇÃO}

As políticas públicas educacionais direcionadas a implantação da informática nas escolas brasileiras surgem a partir de 1981, ano que foi realizado o I Seminário Nacional de Informática Educativa, com participação de educadores de diversos estados brasileiros. Projetos nacionais foram iniciados como o EDUCOM, FORMAR, PRONINFE E PROINFO (BORBA e PENTEADO, 2007). Entretanto, o projeto EDUCOM (computadores na educação), foi lançado pelo Ministério da Educação e Cultura (MEC) em 1983, com o objetivo de criar centros pilotos nas universidades brasileiras para incentivo a pesquisa e utilização dos computadores no âmbito educacional. Cinco instituições foram envolvidas nesse projeto: Universidade Federal do Rio de Janeiro (UFRJ), Universidade de Campinas (UNICAMP), Universidade Federal do Rio Grande do Sul (UFRGS), Universidade Federal de Minas Gerais (UFMG), Universidade Federal de Pernambuco (UFPE). Dentro dessas instituições foram desenvolvidas experiências em relação à inserção de computadores no ensino a nível fundamental e médio (BRASIL, 2013).

Já o projeto intitulado FORMAR (FORMAR I - 1987, FORMAR II - 1989) teve como iniciativa realizar cursos de especialização para pessoas de diversos estados. Desde modo a finalidade do curso seria utilizar esses alunos como multiplicadores em suas cidades de origem. A partir dessa ação, surgiram em dezessete estados brasileiros os Centros de Informática Educacional (CIED). Os cursos do FORMAR propiciaram uma visão ampla dos aspectos que envolvem a informática educativa, referente as questões pedagógicas, possibilitando que cada participante possa escolher dentro das diferentes abordagens as que sejam mais proveitosas para sua afinidade intelectual. Os materiais produzidos nestes cursos e as experiências adquiridas passaram a ser utilizadas como material de referência para o planejamento de outros cursos de formação no país (OLIVEIRA, 2007).

Em 1989 para dar continuidade aos programas anteriores foi lançado pelo MEC o Programa Nacional de informática da Educação - PRONINFE, programa esse que colaborou para a criação de laboratórios e centros para capacitação de professores. O programa visava dar amparo ao desenvolvimento e utilização da informática nos ensinos de 1ㅇ, 2으 e 3 o graus ${ }^{1}$ e educação especial. Também contribui para estimular a criação de diversos centros distribuídos pelo país, estimulando a criação de centros de pesquisa, de capacitação continua e permanente de professores, formação de recursos humanos, além de contribuir para a produção, aquisição, adaptação e avaliação de softwares educativos. Diante das experiências adquiridas com esses projetos foi lançado em 1997 pela Secretaria de Educação a Distância (SEED/MEC), o programa atual de governo chamado PROINFO (Programa Nacional de Informática na Educação), com a finalidade de estimular e dar sustentação para a implantação das tecnologias da informática nas escolas de ensino fundamental e médio em todo território nacional, com a intenção de implantar mais de 200 núcleos até o ano de 2001. Em parceria com outros setores como ministérios, governos municipais, estaduais, e até mesmo com empresas do setor privado, o MEC busca subsídios para realizar avanços no processo de informatização das escolas. Exemplo disso é o Programa Telecomunidade, que utilizando recursos vindos do Fundo de Universalização dos Serviços de Telecomunicações (FUST), em parceria com o Ministério das Telecomunicações, almeja fornecer um computador para cada vinte

\footnotetext{
${ }^{1}$ atuais Ensino Fundamental, Ensino Médio e Graduação
} 
e cinco alunos do ensino médio de todas as escolas brasileiras. Para que se possam criar esses programas, é necessário um envolvimento entre as secretarias estaduais de educação. O projeto PROINFO, necessita de um programa por parte do estado, Programa Estadual de Informática na Educação, para que possa ter condições físicas, manutenção técnica e propostas de capacitação para os professores na área. Um exemplo é o programa lançado no Estado de São Paulo no ano de 1998 denominado, "A escola de cara nova na era da informática". Esse programa reuniu por volta de duas mil escolas, incluindo nível fundamental e médio para a criação de um ambiente de informática (SAI) tendo cinco computadores, duas impressoras, câmeras de vídeo, softwares e conexão com a Internet. O ministério da educação sugere nos Parâmetros Curriculares Nacionais (PCN) assim como nas Diretrizes Curriculares Nacionais da Educação Básica (DCN) que se desenvolvam programas relacionados à utilização das tecnologias em sala de aula em harmonia com as propostas pedagógicas educacionais.

[...] a infraestrutura tecnológica, como apoio pedagógico às atividades escolares, deve também garantir acesso dos estudantes à biblioteca, ao rádio, à televisão, à internet aberta às possibilidades da convergência digital (BRASIL, 2013, p. 25, grifos meus).

Neste momento, faz-se oportuno fazer um parêntese na dependência apresentada no DCN 2013 entre a formação do conhecimento científico e as novas tecnologias.

[...] o conhecimento científico, nos tempos atuais, exige da escola o exercício da compreensão, valorização da ciência e da tecnologia desde a infância e ao longo de toda a vida, em busca da ampliação do domínio do conhecimento científico: uma das condições para o exercício da cidadania (BRASIL, 2013, p. 26).

De acordo com Nascimento (2007), o projeto Proinfo é articulado de forma descentralizada, de responsabilidade do Governo Federal. Dessa forma todas as federações possuem uma unidade, cujo objetivo é introduzir as Tecnologias de Informação e Comunicação (TIC), nas escolas da rede pública de ensino fundamental e médio, juntamente com auxílio das ações dos Núcleos de Tecnologia Educacional (NTE). Esclarece Nascimento (2007, p.33). Os NTE são locais dotados de infraestrutura de informática e comunicação que reúnem educadores e especialistas em tecnologia de hardware e software. Os profissionais que trabalham nos NTE são especialmente capacitados pelo Proinfo para auxiliar as escolas em todas as fases do processo de incorporação das novas tecnologias. A capacitação dos professores é realizada a partir desses núcleos nos quais os agentes multiplicadores dispõem de toda a estrutura necessária para qualificar os educadores a fim de utilizar a internet no processo educacional. Para fornecer apoio tecnológico e suporte para todas as unidades, foi criado o Centro de Experimentação em Tecnologia Educacional (CETE), que fica situado no MEC em Brasília. As principais contribuições do CETE para o programa PROINFO, esta no estabelecimento de redes de comunicação, na divulgação de produtos e dados informativos, na promoção do uso de novas tecnologias por meio de atividades nas áreas de telemática e infraestrutura de informações.

Segundo o Programa Nacional de Informática na Educação, de julho de 1997, o processo de capacitação dos recursos humanos para o planejamento do programa destaca os seguintes aspectos: selecionar e capacitar professores de instituições de ensino superior/técnicoprofissionalizante destinados a fornecer formação de professores multiplicadores; desenvolver uma seleção e formação de técnicos de suporte em informática e telecomunicações; eleger 
professores da rede pública de ensino de 10 e 20 graus para atuarem nas escolas com os equipamentos e softwares do MEC. De acordo com Brasil (1997, p.08) os objetivos principais são:

[...] Estruturar um sistema de formação continuada de professores no uso das novas tecnologias da informação, visando o máximo de qualidade e eficiência;

Desenvolver modelos de capacitação que privilegiem a aprendizagem cooperativa e autônoma, possibilitando aos professores de diferentes regiões geográficas do país oportunidades de intercomunicação e interação com especialistas, o que deverá gerar uma nova cultura de educação a distância;

Preparar professores para saberem usar as novas tecnologias da informação de forma autônoma e independente, possibilitando a incorporação das novas tecnologias à experiência profissional de cada um, visando a transformação de sua prática pedagógica.

De acordo com Brasil (1997), as estratégias de implantação do programa têm por objetivo: descentralizar a formação de capacitação dos docentes e técnicos de suporte; estimular a interação dos professores dando ênfase para a importância de um processo cooperativo no qual professores capacitam professores; incentivar a participação educadores-líderes como monitores; valorizar a experiência profissional dos educadores fazendo uso dela como ferramenta de motivação para sua aliciação no processo estimulando a interação com a comunidade, agregando recursos locais para a capacitação profissional. Nessa perspectiva, Brasil (1997) visa estabelecer resultados satisfatórios para a melhoria da qualidade e ação do sistema educacional público brasileiro com o baixo valor de investimentos, correspondente a US\$72,00 por estudante beneficiado, já incluído nesse valor a montagem de infraestrutura de formação e custeio do profissional por dois anos. Além disso, a proposta pretende fornecer: capacitação de 25.000 docentes, possibilitando entre outros fatores a inserção no mercado de trabalho, a geração direta e indireta de mais empregos; a propagação da informática em novos mercados consumidores, pela ação da publicidade feita pelas vitrines escolares; a contribuição para o revigoramento e a mudança de perfil da economia local, através da formação de profissionais capacitados; a utilização desses recursos pelas comunidades locais em cursos direcionados ao interesse econômico da região; melhoria da gestão escolar e acesso a redes de informações globais. normas têm como objetivo dar uma orientação geral aos autores dos artigos no momento em que forem redigir e, principalmente, quando forem organizar e digitar seus artigos científicos.

Em conformidade com o exposto, podemos entender que o conhecimento científico está diretamente associado aos meios digitais, os quais divulgam de maneira vertiginosa para a população os avanços prometidos pelas descobertas da comunidade científica.

Tendo em vista que o Estado do Paraná disponibiliza esse aporte às escolas, essa pesquisa teve o objetivo de estudar as concepções de professores da rede estadual de educação do Estado do Paraná, sobre a utilização de tecnologias educacionais no ensino de Ciências da Natureza. As discussões foram realizadas com base no Programa Paraná Digital e no material disponível no Portal "Dia a Dia Educação", concebido pela Secretaria de Estado da Educação do Estado do Paraná (SEED/PR). Para isso, a investigação foi conduzida por duas questões, a saber: Como a tecnologia pode contribuir nas aulas de ciências para a aprendizagem dos estudantes? Você utiliza os recursos tecnológicos disponibilizados na escola nas aulas de Ciências? 


\section{METODOLOGIA}

Essa pesquisa foi qualitativa, naturalístico-construtivo, de acordo com Moraes (2006) pois, buscou-se a compreensão dos fenômenos dentro do próprio contexto que estão inseridos os entrevistados. Essa pesquisa foi realizada com base em aplicação de questionários, análise de documentos oficiais, além de estudos realizados em artigos e livros da área da Educação. Para assegurar a privacidade de todos os envolvidos, os nomes próprios dos sujeitos, assim como os endereços e o nome da escola foram omitidas. Os nomes dos sujeitos foram codificados com letras $A, B, C$ etc. A escola escolhida é considerada como sendo uma das mais tradicionais do município, que possui 3 turnos (matutino, vespertino e noturno) e possui, aproximadamente, 1500 estudantes. Os sujeitos da pesquisa foram os docentes da disciplina de Ciências da Natureza do Ensino Fundamental II, que abrange as turmas do 60 aos 9 anos. O grupo de entrevistados foi composto de 5 docentes, com faixa etária entre 21 e 46 anos, formado por $65 \%$ do sexo feminino e 35\% masculino, com graduação em licenciatura plena e/ou curta em Ciências Biológicas.

A coleta de dados foi realizada por meio de entrevista semiestruturada, com um roteiro padrão de perguntas contendo duas questões: Como a tecnologia pode contribuir nas aulas de ciências para a aprendizagem dos estudantes? Você utiliza os recursos tecnológicos disponibilizados na escola nas aulas de Ciências?

Os depoimentos dos entrevistados foram transcritos literalmente em textos, que foram tratados por meio da Análise Textual Discursiva - ATD (MORAES; GALIAZZI, 2011). Nessa metodologia de análise qualitativa, são identificadas as ideias contidas em cada fragmento de frase, compondo unidades de significados (numerados por meio de códigos). Essas unidades de significado são agrupadas em função de significados semelhantes, constituindo categorias iniciais, as quais são reagrupadas, compondo categorias intermediárias, que novamente reagrupadas, se constituem em categorias finais. Com base no conteúdo das categorias finais, é possível organizar metatextos, os quais descrevem e interpretam as ideias emergentes de cada categoria analisada.

\section{PROGRAMA PARANÁ DIGITAL}

No ano de 2003 foi lançado no estado do Paraná o Programa Paraná Digital (PRD), sob administração da Secretaria de Estado da Educação SEED/PR, segundo a cartilha publicada pela Secretaria de Estado da Educação de Curitiba 2012 este projeto visa expandir o número de equipamentos e o acesso as mídias tecnológicas, buscando um grau de abrangência mais ambicioso que os programas anteriores ${ }^{2}$. Dentro desse contexto, o programa se baseia em três pilares fundamentais (PARANÁ, 2010, p. 68), a saber:

a) Repasse de equipamentos e estabelecimento de conectividade em todas as escolas públicas estaduais;

b) Criação e formalização de um canal institucional colaborativo Portal Dia a dia Educação - para produção e publicação de materiais didáticos digitais em ambiente web;

c) Formação de educadores para uso pedagógico desses recursos utilizando a plataforma Linux de software livre.

${ }^{2}$ EDUCOM, FORMAR, PROINFE E PROINFO. 
O PRD tem como objetivo a promoção da inclusão digital no Estado do Paraná, colaborando dessa forma com a melhoria da qualidade da educação básica por intermédio do uso das novas tecnologias da informação e da comunicação. O objetivo do programa é promover o uso pedagógico das Tecnologias da informação e comunicação (TIC), disponibilizando a professores e estudantes da rede pública. A proposta do programa contempla o repasse de computadores com acesso à internet para as instituições de ensino, disponibilizando um espaço virtual de aprendizado. A proposta pretende atingir mais de 2.100 escolas públicas localizados nos 399 municípios do Paraná, atendendo a um universo de 1,5 milhão de estudantes que estão matriculados no ensino público, uma média de 51 mil professores, funcionários da SEED e 32 Núcleos Regionais de Educação - NRE (PARANÁ, 2010, p.11).

Entre os parceiros para a implantação deste programa de acordo com Paraná (2010) estão: o Programa das Nações Unidas para o Desenvolvimento (PNUD) que colabora com a aquisição de materiais, além de prestar auxílio nas questões burocráticas do sistema como pagamento aos prestadores de serviços ligados as tarefas e execuções de ações ligadas ao PRD; a Agência Brasileira de Cooperação, integrante da estrutura do Ministério das Relações Exteriores (MRE) que tem entre suas funções coordenar, negociar, implementar e assessorar programas do PRD, que necessitam de uma relação de cooperação técnica entre acordos firmados pelo Brasil e demais países de organizações internacionais; a Companhia Paranaense de Energia (COPEL), que trabalha basicamente com a manutenção e infraestrutura das questões relacionadas com a conectividade, mais especificamente na rede externa de cabeamento coligado também a supervisão de tráfego e banda e a Companhia de informática do Paraná (CELEPAR), que monitora a conexão e executa tarefas de atualização de sistemas operacionais do PRD. Sendo assim, a CELEPAR, juntamente com a COPEL, são órgãos responsáveis pela rede externa e pela conexão com a internet realizada por fibra óptica. A Secretaria de Estado da Ciência e Tecnologia e o Departamento de Informática da Universidade Federal do Paraná (SETI/UFPR) criaram os recursos relacionados a hardware e software para o PRD, incluindo dispositivos para o controle remoto do acesso à Internet. A par disso, a SEED/PR, com o apoio da Diretoria de Tecnologia Educacional (DITEC), são responsáveis pela implantação do PRD, a partir do trabalho desenvolvido pelas Coordenações da Diretoria.

Diante deste suporte proposto pelas instâncias políticas e econômicas, buscamos a partir dos dados obtidos com esta pesquisa, apresentar e discutir a efetivação dos resultados em âmbito escolar.

\section{ANÁLISE DOS DADOS E DISCUSSÕES}

Após a análise das narrativas dos sujeitos da investigação, emergiu uma categoria de cada pergunta na seguinte ordem:

a) Tecnologia contribui para aulas mais interessantes;

b) Falta de manutenção dos equipamentos.

Assim, passamos a descrever os conteúdos dessas categorias. 


\subsection{Tecnologia contribui para aulas mais interessantes}

Nesta categoria, observamos o conjunto de unidades de significado que abordam os principais motivos pelos quais os docentes acreditam ser importante utilizar as tecnologias em sala de aula no ensino de Ciências. No discurso dos sujeitos, percebemos que todos se mostraram favoráveis ao uso das tecnologias em sala de aula. Segue alguns exemplos:

São tantas as possibilidades que as tecnologias nos proporcionam, que seria impossível enumerá-las. (SUJEITO C)

A internet é um ambiente muito rico, onde temos muitas possibilidades para trabalhar os conteúdos de Ciências. (SUJEITO A)

De acordo com Bizzo (2008), é necessário considerar a importância em fazer uso de atividades diferentes em sala de aula, pois isso estimula a capacidade do estudante em desenvolver habilidades diferentes. Em razão disso, o professor deve fazer uso de todas as ferramentas que estão ao seu alcance, criando ambientes diferenciados que despertam o interesse e a curiosidade do aluno, estimulando-os a expor suas ideias e dúvidas. De acordo com Perrenoud (2000, p. 125), a escola deve se adequar a realidade a qual vivemos, pois "as crianças nascem em uma cultura em que se clica, e o dever dos professores é inserir-se no universo dos estudantes." Sendo assim, podemos dizer que se a escola não se adequar a realidade tecnológica existente, podemos presumir uma desqualificação do ambiente escolar.

Para Kenski (2003), as tecnologias sempre estiveram presentes em nossas vidas, pois as necessidades rotineiras, como trabalhar, alimentar-se, dormir ou até mesmo se deslocar para lugares diferentes, são possíveis graças às tecnologias à disposição. Desse modo, podemos dizer que tudo que é utilizado diariamente, como por exemplo, uma faca, caneta, giz, papel são chamadas de ferramentas tecnológicas. Sendo assim, a Era Tecnológica não é novidade para o atual momento, existindo desde o início das civilizações, cada época com suas tecnologias, a Idade da Pedra, do Bronze, até a nossa atualidade tecnológica. De acordo com Kenski (2003, p. 26), a era atual se caracteriza como de extrema velocidade no universo informacional criando "a necessidade de permanente atualização do homem para acompanhar essas mudanças".

Furman (2009, p. 7), afirma que ao ensinar Ciências o professor coloca-se em uma situação de muita responsabilidade, pois a didática em Ciências estabelece nos estudantes a necessidade de aprenderem a resolver problemas, analisar informações e desenvolverem competências para prepará-los para os desafios impostos pela vida. Nessa perspectiva, a autora sugere que o professor tem o papel de "estimular a curiosidade que o aluno já traz consigo como plataforma sobre a qual estabelecer as bases do pensamento científico e desenvolver o prazer por continuar aprendendo". Nesse sentido, a autora sugere que no ensino de Ciências deve-se "utilizar esse desejo natural de conhecer o mundo que todos os alunos trazem para a escola como plataforma sobre a qual possam construir ferramentas de pensamento que lhes permitam compreender como as coisas funcionam, e pensar por eles mesmos".

Sendo assim, para que a aprendizagem aconteça, é necessário um conjunto de situações favoráveis dentro da sala de aula, para estimular o plano cognitivo do aluno diante das situações propostas pelo professor. Nesse sentido, pesquisadores que discutem e investigam os processos de aprendizagem, indicam que as atividades de ensino devem ser planejadas de modo a aproveitar, complementar, desenvolver e transformar ideias, teorias e conhecimentos que os estudantes, em 
muitas situações, trazem consigo. No que diz respeito do papel do docente e sua prática, Salles (2007, p. 150) afirma que:

[...] o uso de diferentes metodologias por parte do professor indica a sua postura quanto a sua concepção de ciências, a qual é repassada aos seus alunos. $O$ docente sem concepção de ciências apresenta conteúdos de forma rotineira, cristalizada, e não constrói conhecimentos.

A possibilidade de acesso a um novo universo informacional altera o contexto social em que vivemos, trazendo mudanças nas regras de convivência e acessibilidade às informações. De acordo com Pais (2008), ao considerar que, em um passado recente, anterior ao uso do computador o professor tinha a função de centralizar toda a fonte de conhecimentos para si, hoje o professor não assume mais o papel de fonte de acesso a informações. O resultado dessa condição traz consigo a importância do desempenho do professor em trabalhar com a multiplicidade informacional na construção do aprendizado.

A utilização da informática na educação nos faz refletir e considerar aspectos relacionados à síntese do conhecimento a partir das informações obtidas. De acordo com Pais (2008, p. 19), "A síntese de um conhecimento ocorre sempre a partir de informações, mas o conhecimento em si mesmo não deve ser confundido com os dados informativos". Dessa forma, podemos dizer que o desafio da aprendizagem está em transpor os dados isolados obtidos com as informações, para a elaboração de conhecimentos. Assim, podemos dizer que o uso da informática na escola se torna uma importante ferramenta para obtenção de informações, estas, sendo matérias-primas para elaborar ação de conhecimento. Dado o exposto, Pais afirma que (2008, p. 25), "esse é um dos grandes desafios para a ação da escola na atualidade. Viabilizar-se como espaço crítico em relação ao uso e à apropriação dessas tecnologias de comunicação e informação" contexto, outra questão importante ressaltar é como trabalhar com o excesso de informações disponibilizadas na internet. A respeito disso, Pais (2008, p. 59) questiona: como proceder a uma seleção das páginas que poderão contribuir para a solução do problema pesquisado? A estratégia de consultar algumas páginas aleatórias é suficiente para uma aprendizagem significativa? Quais são as estratégias adequadas para proceder a depuração de uma consulta na internet? Segundo Borba e Penteado (2007), outra questão que surge com a inserção dos computadores, é a chamada zona de risco, que consiste em problemas técnicos e dúvidas que podem surgir durante o uso do computador. Os autores admitem que são várias as dificuldades que o professor e o aluno enfrentam diante dessa questão. Como exemplo, menciona-se o professor que, ao preparar uma aula envolvendo o uso da informática, depara-se com o fato das máquinas estarem desconfiguradas para o programa que pretendia usar, devido a uma aula anterior de outra disciplina. Essa situação pode interromper completamente a atividade programada. Diante dessa situação, seria importante ter à disposição do professor um técnico de informática para solucionar o problema no instante, mas perante esse problema "sabemos que são poucas as escolas que possuem um técnico para cuidar da sala de informática e garantir condições de trabalho" (BORBA; PENTEADO, 2007, p.57). Outra questão relacionada ao tema é, que por mais experiente que seja o professor, pode acontecer situações em que os alunos questionem como proceder na elaboração de sua tarefa. Um exemplo disso, é o fato de existir diversos caminhos e combinações de teclas, que podem levar a repostas iguais por caminhos diferentes. De uma forma geral, o uso da informática na educação escolar pode oferecer novas regras para o funcionamento do sistema didático, possivelmente sinalizando para exigência de maior autonomia e iniciativa do estudante. Segundo Rocha (2008), a partir de estudos de 
Ferreira (2002), o computador não é um instrumento autônomo, precisa receber comandos para realizar funções e tarefas, possuindo o poder de estimular a capacidade de decisão, iniciativa e autonomia do estudante. Além disso, desenvolve o raciocínio lógico, pois diante de situações inesperadas que podem surgir, o estudante precisa levantar hipóteses, analisar estratégias, criar métodos alternativos, ou seja, adotar diversos caminhos para seguir. Nessa perspectiva, o uso do computador também contribui para a expressão emocional, que através da busca por imagens, textos e vídeos, pode de alguma forma expressar sinais de raiva, afetividade ou frustrações.

Dando prosseguimento a narrativa dos sujeitos, alguns assumiram que a utilização dos computadores se faz importante nas aulas de ciências para visualização de vídeos e imagens. Segue exemplos:

O computador é importante, pois podemos usar para ver vídeos relacionados ao conteúdo, fica mais real para o aluno (SUJEITO A)

Acho interessante utilizar para ver vídeos e imagens nas aulas de ciências (SUJEITO B)

De acordo com Krasilchik (2004), a utilização de equipamentos audiovisuais em determinadas situações de aprendizagem são imprescindíveis no ensino de Ciências para observar comportamento de animais, rituais de acasalamento, paisagens exóticas, sons de animais, processos muitos lentos ou rápidos para visualizar na sua atividade natural, entre outros. Essa utilização pode ser tanto para trabalhar conceitos novos, como para rever situações já discutidas em sala de aula, ou ainda para visualizar situações nunca vistas antes pelos estudantes. Em virtude das considerações, fica evidente que a utilização das tecnologias de forma adequada favorece o aprendizado no ensino de ciências.

Dando prosseguimento as categorias que emergiram de nossa análise, trataremos a seguir da questão da Falta de manutenção dos equipamentos, questão manifesta pelos sujeitos entrevistados. Buscaremos contrapor o discurso com as políticas públicas do Paraná Digital (PRD), que tem como objetivo a promoção da inclusão digital no Estado do Paraná, que tem como objetivo melhorar a qualidade da educação básica por intermédio do uso das novas tecnologias da informação.

\subsection{Falta de manutenção dos equipamentos}

A partir da resposta da pergunta - "Você utiliza os recursos tecnológicos disponibilizados na escola nas aulas de Ciências?", foi percebido que todos os entrevistados foram categóricos em responder que não utilizam pela falta de manutenção dos equipamentos.

De acordo com as Coordenações Regionais de Tecnologia na Educação (CRTE) existem 65 profissionais qualificados responsáveis pelas ações e atividades ligadas a assessoria técnica e suporte para cuidar da instalação e manutenção dos computadores em todo estado. Em vista das notas do Núcleo de Tecnologia na Educação (NTE) do Estado do Paraná (2003), o município da pesquisa conta com cinco profissionais atuantes, para um total de 31 escolas com os Laboratórios de Informática (PARANÁ, 2010). Mesmo o número parecendo pouco para atender todas as escolas, ainda assim parece ser suficiente para o NTE. Curiosamente, segundo informações no site da secretaria da educação do Paraná no ano de 2014, o que evidenciamos foi 1 profissional de suporte 
técnico para todas as escolas do município. Essa verificação foi concordante com as respostas dos entrevistados:

Péssimo gerenciamento dos equipamentos disponíveis (Sujeito B).

Falta de manutenção dos equipamentos, dessa forma não tem como utilizá-los (Sujeito C).

Em contrapartida, a falta de manutenção dos equipamentos na escola, um entrevistado fez questão de salientar a qualidade do material disponibilizado no portal Dia a dia Educação.

Temos um rico material a disposição na internet (portal dia a dia) o que falta são os equipamentos (Sujeito D).

O Portal Dia a Dia Educação é a página eletrônica disponível na Internet, concebida pela SEED e gerenciado pela Coordenação de Mídia Impressa e Web Diretoria de Tecnologia Educacional (DITEC). O site disponibiliza diversos materiais didáticos e conteúdos pedagógicos em espaço virtual, local que estudantes e educadores da rede pública paranaense encontram conteúdos pedagógicos e materiais didáticos digitais. Entre os recursos didáticos que o portal dia a dia educação disponibiliza ao educador, a cartilha apresenta:

[...] Artigos, Teses e Dissertações - Neste espaço são disponibilizados artigos, dissertações e teses da área educacional por meio da participação da comunidade de usuários do Portal Dia a dia Educação. Espaço de divulgação do conhecimento e de colaboração na troca de saberes, dentro do espírito de coletividade da web. Socialização de conhecimento, inclusão digital, quebra de barreiras geográficas, econômicas e idiomáticas;

Banco de Imagens - Disponibiliza centenas de imagens, ilustrações e fotografias, já categorizadas em unidades temáticas adequadas à utilização em atividades pedagógicas;

Bibliotecas - Espaço com links de acesso a bibliotecas nacionais e internacionais, tornando muito mais fácil a realização de pesquisas de obras literárias, documentais, dissertações, teses, incluindo acervo de obras raras;

Cadernos Pedagógicos - Espaço dos Departamentos de Educação da SEED, que disponibiliza a produção de materiais didático-pedagógicos - entre eles, os Objetos de Aprendizagem Colaborativa (OAC) e Projeto Folhas (Livro Didático Público);

Catálogo de sítios - Mais de 2 mil sítios classificados em 24 categorias. Cada endereço da web vem acompanhado de um breve descritivo, número de acessos e avaliação de usuários, através da publicação de uma nota;

Dicionário da Língua Portuguesa - Hiperlink para um dicionário virtual da Língua Portuguesa, ferramenta fundamental para o desenvolvimento linguístico, cultural e social;

Domínio Público - Link dedicado ao Portal Domínio Público, que permite a coleta, integração e preservação de obras literárias, artísticas e científicas (na forma de textos, sons, imagens e vídeos) de domínio público ou que tenham sua divulgação devidamente autorizada, constituindo patrimônio cultural brasileiro e universal; 
Filmes - Resenhas de grandes obras da Sétima Arte, indicações de temáticas do cotidiano escolar que podem ser abordadas a partir destas resenhas, além de coletâneas de artigos sobre cinema e educação;

Literatura on-line - Disponibiliza, para leitura e download, diversas obras da literatura brasileira e paranaense. Inclui algumas obras em áudio, o que representa um grande diferencial do Portal Dia a dia Educação, já que favorece os portadores de necessidades especiais; 36

Livro didático público - Coletânea de textos do Projeto Livro didático público, de autoria dos docentes da rede estadual de ensino, para serem utilizados em sala de aula. É possível enviar comentários sobre a experiência do uso desse material: mais um espaço de interação e construção coletiva no Portal Dia a dia Educação;

Mapas - Oferece acesso a diversos tipos de mapas, incluindo ferramentas de mapas interativos;

Museus - Promove uma viagem virtual por museus nacionais e internacionais. 0 internauta escolhe o museu que deseja conhecer e é redirecionado para o sítio respectivo, iniciando a navegação. Mais um exemplo do caráter socializador promovido pelo Portal Dia a dia Educação, colocando o conhecimento e o saber ao alcance de todos;

Simuladores e Animações - Espaço composto por simuladores e animações aplicados à educação, classificados por disciplinas. Estes recursos hipermidiáticos são uma poderosa ferramenta pedagógica porque permitem a visualização gráfica e a interação ativa com conteúdos disciplinares, temáticas educativas e problemáticas em estudo; (PARANÁ, 2010, p. 35-36).

O Portal "Dia a Dia Educação" teve início no ano de 2003, atualmente conta com uma equipe multidisciplinar que o mantém em funcionamento 24 horas por dia. No site são postados e disponibilizados materiais didáticos e conteúdos pedagógicos. Esses são produzidos pelas coordenações da DITEC e da SEED. A finalidade do portal é colaborar com a construção do conhecimento, oferecendo um espaço novo que desperta interesse dos alunos, colaborando para a criação de vivências amplas e significativas para o desenvolvimento do processo de ensino.

Essas informações nos parecem causar uma diferença de investimentos por parte das coordenações da DITEC e da SEED em relação às CRTE, pois, embora tenha um material atualizado e disponibilizado nas redes de comunicações mantidas por ambas, os equipamentos (computadores) de responsabilidade da CRTE se encontram sem condições de uso na escola. De maneira informal após a resposta das perguntas, surgiram depoimentos que chamaram a atenção, acrescentando possíveis soluções para que os recursos fossem utilizados de maneira satisfatória, tais como:

Deveria ter funcionários na escola para monitorar os equipamentos (SUJEITO C).

Não adianta nada comprar computadores e botar na escola sem dinheiro para manutenção de peças e acessórios (SUJEITO B).

Isso demonstra a falta de continuidade das políticas públicas, causando um desperdício do dinheiro público em projetos que não chegam a ser efetivados. 


\section{CONSIDERAÇÕES FINAIS}

O PRD surgiu como uma fusão dos programas anteriores com a finalidade de proporcionar aos estudantes materiais didáticos por meio dos computadores. Observamos que as condições precárias dos equipamentos nas escolas não possibilitaram a efetivação dos objetivos finais do Programa. Muitos dos materiais, considerados pelos professores de boa qualidade, não chegaram sequer a serem utilizados, deixando a lacuna sobre sua eficácia no processo de aprendizado em sala de aula.

A primeira vista, os resultados da pesquisa indicaram que os professores da escola investigada não fazem uso dos recursos tecnológicos disponibilizados na instituição. $O$ motivo relatado está na falta de manutenção das máquinas. A origem do problema parece estar nos setores responsáveis pela manutenção desses equipamentos, as CRTE. Ainda em relação às concepções dos professores entrevistados podemos complexificar a discussão ao considerar que, mesmo que existam justificativas que dificultem a utilização dos recursos disponibilizados pelo programa PRD, entendemos que caberia ao professor que assim quisesse, utilizar os recursos disponibilizados no site portal Dia a Dia educação em suas aulas, pois partimos do entendimento que assim como o conhecimento científico, os programas desenvolvidos pelos meios digitais avançam de forma positiva, com o objetivo de aprimorar uma situação. Mas vale lembrar, que a efetivação dessas ações passam por questões políticas econômicas e sociais, estas últimas, advindas da atitude de cada sujeito que é interpelado por diversos fatores. Desta maneira, podemos dizer que a atitude (ação social) do sujeito integram os resultados das ações educativas. Sendo assim, entendemos que as concepções dos entrevistados partem de uma contingência complexa, que não são estritamente resultado de condições somente políticas e econômicas.

\section{REFERÊNCIAS BIBLIOGRÁFICAS}

1. BIZZO, N. Ciências: fácil ou difícil? São Paulo: Ática, 2008.

2. BORBA, M. C. PENTEADO, M. G. Informática e educação matemática. Belo Horizonte: Autêntica, 2007.

3. BRASIL. Ministério da Educação. Secretaria de Educação Básica. Secretaria de Educação Continuada, Alfabetização, Diversidade e Inclusão. Secretaria de Educação Profissional e Tecnológica. Conselho Nacional da Educação. Câmara Nacional de Educação Básica. Brasilia, 2013.

4. BRASIL. Ministério da Educação e do Desporto - MEC. Secretaria da Educação a Distância SEED. Programa Nacional de Informática na educação. PROINFO. Diretrizes. Brasília, 1997.

5. FURMAN, M. O ensino de ciências do ensino fundamental: colocando as pedras fundacionais do pensamento científico. Sangari Brasil, São Paulo, outubro 2009.

6. MORAES, R. Da noite ao dia: tomada de consciência de pressupostos assumidos dentro das pesquisas sociais. Porto Alegre, 2006. (Texto inédito)

7. MORAES, R.; GALIAZZI, M. C. Análise textual discursiva. 2 ed. ljuí: Editora UNIJUÍ, 2011.

8. NASCIMENTO, J. K. F. Informática aplicada à educação. Brasília: Universidade de Brasília, 2007.

9. OLIVEIRA, R. Informática Educativa: magistério, formação e trabalho pedagógico. São Paulo: 
Papirus, 2007.

10. PAIS, L. C. Educação escolar e as tecnologias da informática. Belo Horizonte: Autêntica, 2008.

11. PARANÁ (Estado). Secretaria de Estado da Educação. Paraná digital - tecnologias de informação e comunicação nas escolas públicas paranaenses. Secretaria de Estado da Educação, Curitiba: SEED, 2010.

12. PERRENOUD, P. 10 novas competências para ensinar. Porto Alegre: Artes Médicas Sul, 2000.

13. KENSKI, V. M. Tecnologias e ensino presencial e a distância. Campinas: Papirus, 2003.

14. KRASILCHIK, M. Prática de Ensino de Biologia. São Paulo: Editora da Universidade de São Paulo, 2004.

15. ROCHA, S. S. D. O uso do Computador na Educação: a Informática Educativa In: Revista Espaço Acadêmico. № 58, junho de 2008. Disponível em: <http://www.espacoacademico.com.br/ 085/85rocha.htm>. Acesso em 18 jul. 2012. 